\title{
Hambatan dan Strategi komunikasi efektif dalam perawatan kanker : Penelitian Fenomenologi
}

\author{
Minanton ${ }^{1}$, Erna Rochmawati ${ }^{2}$ \\ ${ }^{1}$ Dosen Program S1 Keperawatan STIKES Surabaya \\ ${ }^{2}$ Dosen Program Studi Magister Keperawatan Universitas Muhammadiyah Yogyakarta \\ Alamat Korespondensi: minantonsevennain@gmail.com
}

\begin{abstract}
Abstrak
Komunikasi terapeutik diakui sebagai kunci untuk perawatan kanker yang berkualitas, tetapi komunikasi perawat-pasien dalam perawatan kanker adalah hal menantang dan kompleks, selain itu data yang mengeksplorasi komunikasi perawat-pasien masing sangat kurang. Tujuan penelitian ini adalah untuk melaporkan hasil temuan tentang perspektif perawat, pasien dan keluarga terkait hambatan dan strategi komunikasi dalam perawatan kanker. Penelitian ini merupakan penelitian fenomenologi yang dilakukan di RS. PKU Muhammadiyah Yogyakarta. Respoden penelitian ini adalah 16 orang (4 perawat, 7 pasien dan 5 anggota keluarga) yang dipilih melalui purposive sampling dan dilakukan wawancara semi terstruktur. Semua hasil wawancara di transkrip dan dianalisis menggunakan metode Collaizzi. Hasil penelitian ini mengidentifikasi dua tema yaitu hambatan berkomunikasi efektif dan manajemen berkomunikasi. Hambatan komunikasi dikontruksi oleh sikap mengabaikan, tingkat pendidikan dan kondisi psikologis. Manajemen berkomunikasi terdiri dari persiapan diri, validasi pengetahuan pasien, dan struktur penyampaian informasi. Kesimpulan dalam penelitian ini yaitu komunikasi terapeutik merupakan pondasi untuk mempromosikan kualitas perawatan kanker. Hambatan berkomunikasi perlu dimanaje dengan baik dengan mengimplementasikan tindakan untuk menjaga interaksi dan pertukaran informasi seperti mempersiapkan diri, mevalidasi pemahaman pasien, dan penyampaian informasi secara terstruktur.
\end{abstract}

Kata Kunci: Hambatan berkomunikasi, kanker, komunikasi terapeutik, strategi komunikasi.

\begin{abstract}
Therapeutic communication is recognized as the key to quality cancer care, but nurse-patient communication in cancer care is challenging and complex, additionally data exploring individual nursepatient communication is lacking. The purpose of this study is to report findings on the perspectives of nurses, patients, and families regarding communication barriers and strategies in cancer care. This study used a qualitative phenomenological method conducted at the PKU Muhammadiyah Yogyakarta hospital. Sixteen participants ( 4 nurses, 7 patients, and 5 family members) were selected through purposive sampling and conducted semi-structured interviews. All of the interview results were transcribed and analyzed using Colaizzi's method. The results of this study identify two themes, namely barriers to effective communication and communication management. Communication barriers are constructed by ignorance, education level, and psychological conditions. Communication management consists of self-preparation, validation of patient knowledge, and structures for delivering information. The conclusion is that therapeutic communication is the foundation for promoting the quality of cancer care. Communication barriers need to be managed properly by implementing measures to maintain interaction and exchange of information such as self-preparation, validating patient understanding, and conveying information in a structured manner.
\end{abstract}

Keywords: Cancer, communication barriers, communication strategies, therapeutic communication 


\section{PENDAHULUAN}

Kanker adalah penyakit dengan karakteristik pertumbuhan sel tidak normal dan tidak terkontrol yang dapat menyebar (metastasis) ke organ lain. Pertumbuhan sel tidak normal ini berbeda dengan sel-sel normal, baik itu secara struktur maupun fungsi, dimana pertumbuhannya secara terus menerus, tanpa memiliki tujuan, tidak terkendali, dan merusak jaringan di sekitarnya (American Cancer Society, 2018; Stephens \& Aigner, 2016).

Kanker merupakan pembunuh nomor dua di seluruh dunia, yaitu 9,8 juta orang meninggal di tahun 2018. Prevalensi penyakit kanker di Indonesia sendiri terus meningkat dari tahun ke tahun. Berdasarkan hasil Riset Kesehatan Dasar (Riskesdas) tahun 2018, tingkat prevalensi kasus kanker adalah 1,8 per 1.000 penduduk meningkat dari 1,4 per 1.000 di tahun 2013. Data WHO, 2018 menyebutkan jumlah penderita kanker di Indonesia ditahun yang sama yaitu 348.809 kasus dengan total kematian 207.210(Riskesdas, 2018; WHO, 2018).

Kanker dapat menuntun penderita untuk mengevaluasi kembali makna, tujuan, dan prioritas hidupnya. Diagnosis kanker merupakan situasi yang emosional, berat dan diliputi ketidakpastian bagi penderita dan keluarganya. Dalam keadaan seperti ini, pasien dan keluarganya memerlukan informasi dan dukungan yang sesuai untuk memenuhi kebutuhan mereka. Perawat perlu mengenali masalah akibat kanker dan kebutuhan pasien(Ellington et al., 2017; Khoshnazar et al., 2016).

Komunikasi sangat penting dan memainkan peran utama dalam memenuhi kebutuhan biopsikososial dan spiritual pasien kanker dan keluarganya. Komunikasi perawat dan pasien kanker memiliki tiga fungsi penting yaitu terciptanya proses hubungan interpersonal yang efektif, pertukaran informasi, dan memfasilitasi pengambilan keputusan yang tepat. Komunikasi ini merupakan faktor yang menentukan kualitas pelayanan kanker dan hasil akhir kesehatan pasien(Hasan \& Rashid, 2016; Khoshnazar et al., 2016; Prip et al., 2019).

Komunikasi yang efektif dianggap sebagai kunci untuk pelayanan kanker yang baik. Pertukaran informasi, pemikiran dan perasaan antara perawatpasien harus dipahami dan sesuai dengan kebutuhan pasien. Pemberian informasi yang tidak sesuai dengan kebutuhan pasien dianggap sebagai komunikasi yang buruk. Komunikasi yang buruk berdampak negatif terhadap status kesehatan pasien(Prip et al., 2019; Weert et al., 2013).

Meskipun bukti menunjukkan komunikasi adalah faktor utama dalam pelayanan pasien kanker, komunikasi diakui sebagai hal menantang dan kompleks. Kekompleksitas itu meliputi aspek perawatan kanker yang diliputi ketidakpastian dan ketidakberdayaan; kebutuhan informasi penderita kanker berubah seiring perjalanan penyakitnya; perawatan kanker tidak hanya terpusat pada penderita tetapi juga keluarga terdekatnya(Chan et al., 2018; Khoshnazar et al., 2016).

Data tentang komunikasi perawat dan pasien kanker masih sangat kurang dan masih didominasi komunikasi dokter dan pasien. Oleh karena itu, kami melaporkan temuan dari studi fenomenologi yang dilakukan di unit onkologi rumah sakit tentang perspektif perawat, pasien dan keluarga tentang hambatan dan strategi komunikasi dalam perawatan kanker.

\section{METODE PENELITIAN}

$\begin{array}{ccr}\text { Metode } & \text { penelitian yang } \\ \text { digunakan yaitu } & \text { kualitatif dengan }\end{array}$


pendekatan fenomenologi. Penelitian ini dilakukan di bangsal onkologi RS PKU Muhammadiyah Yogyakarta pada bulan Maret sampai April. Setelah mendapat izin penelitian dari rumah sakit, peneliti mendaftarkan peserta yang sesuai kemudian memperkenalkan diri dan menjelaskan tujuan serta proses penelitian untuk mendapat inform consent.

Jumlah partisipan dalam penelitian ini sebanyak 16 partisipan (4 perawat, 7 pasien kanker dan 5 keluarga pasien kanker), dipilih melalui purposive sampling dengan kriteria pasien kanker stadium 2-4, menjalani kemoterapi, pasien kanker dewasa dengan usia $\geq 18$ tahun $\leq 70$ tahun; Anggota keluarga yang mendampingi dan merawat pasien (primer); perawat yang memiliki pengalaman dalam merawat pasien kanker $\geq 1$ tahun dan minimal bergelar diploma keperawatan.

Pengumpulan data dilakukan dengan wawancara semi terstruktur yang direkam dengan alat perekam suara. Wawancara berlangsung antara 18 menit hingga 46 menit. Wawancara dimulai dengan pertanyaan utama yaitu bagaimana pengalaman anda berkomunikasi antara perawat-pasien? Kemudian digali dengan pertanyaan: bagaimana memulai komunikasi? bagaimana perasaanmu berkomunikasi sama perawat/pasien/keluarga? Hambatan apa yang anda alami ketika berkomunikasi? Bagaimana cara anda mengatasi tantangan berkomunikasi?. Semua data wawancara ditranskripsikan dan dianalisis secara bersamaan menggunakan metode Collaizzi(Polit \& Beck, 2012).

Untuk memastikan keabsahan data, peneliti melakukan bracketing dan validasi ke partisipan (member checking), memperpanjang waktu koleksi data, audit trial dan memberikan gambaran lengkap dari hasil temuan untuk memungkinkan pembaca mengkaji penerapan data ke konteks lain(Chesnay, 2014; Holloway et al., 2010).

Penelitian ini telah mendapatkan sertifikat kualifikasi etik nomor 430/ KEP-UNISA/I/2019 dari Komisi Etik Universitas 'Aisyiyah Yogyakarta.

\section{HASIL PENELITIAN}

Temuan ini mengidentifikasi komunikasi perawat-pasien dalam perawatan kanker memiliki beberapa tantangan yang dirasakan oleh perawat, namun disaat bersamaan perawat juga mengetahui bagaimana cara supaya hambatan/tantangan itu tidak sampai mengabaikan pemenuhan kebutuhan pasien.

Karakteristik demografi perawat, pasien dan keluarga, termasuk usia, jenis kelamin, tingkat pendidikan, pengalaman (karakteristik perawat), durasi dan jenis kanker (karakteristik pasien), dan ikatan keluarga, ditunjukkan pada Tabel 1

Table 1.

Karakteristik partisipan

\begin{tabular}{clcrr}
\hline \multirow{2}{*}{ Responden } & \multicolumn{1}{c}{ Kategori } & Min-Maks & $\mathbf{n}$ & \% \\
\hline \multirow{5}{*}{ Perawat $(\mathrm{p})$} & Umur & & & \\
& Jenis kelamin & 0 & $0 \%$ \\
& Laki-laki & & 4 & $100 \%$ \\
\cline { 2 - 4 } & Perempuan & Pendidikan & 2 & $50 \%$ \\
& D3 & 2 & $50 \%$ \\
\hline & S1 & & \\
\cline { 2 - 4 } & Pengalaman & $7-10$ tahun & & \\
\hline
\end{tabular}




\begin{tabular}{|c|c|c|c|}
\hline & Umur & 28-60 tahun & \\
\hline & Jenis Kelamin & & \\
\hline & Laki-laki & 0 & $0 \%$ \\
\hline & Perempuan & 7 & $100 \%$ \\
\hline & Pendidikan & & \\
\hline & SD & 1 & \\
\hline \multirow[t]{12}{*}{ Pasien (ps) } & SMA & 3 & \\
\hline & S1 & 3 & \\
\hline & Jenis Kanker & & \\
\hline & Payudara & 5 & $72 \%$ \\
\hline & Kulit & 1 & $14 \%$ \\
\hline & Paru-paru & 1 & $14 \%$ \\
\hline & Stadium & $2-4$ & \\
\hline & Umur & 42-64 tahun & \\
\hline & Jenis Kelamin & & \\
\hline & Laki-laki & 3 & $60 \%$ \\
\hline & Perempuan & 2 & $40 \%$ \\
\hline & Pendidikan & & \\
\hline \multirow{7}{*}{ Keluarga (k) } & SD & 1 & $20 \%$ \\
\hline & SMA & 2 & $40 \%$ \\
\hline & S1 & 2 & $40 \%$ \\
\hline & Hub. Keluarga & & \\
\hline & Anak & 2 & $40 \%$ \\
\hline & Kakak & 1 & $20 \%$ \\
\hline & Suami & 2 & $40 \%$ \\
\hline
\end{tabular}

Hasil analisis Collaizi mengidentifikasi 2 tema yaitu hambatan berkomunikasi efektif dan managemen berkomunikasi.

\section{Hambatan berkomunikasi efektif}

Tema ini dijelaskan oleh partisipan sebagai kesulitan yang membatasi interaksi dan pertukaran informasi perawat pasien/keluarga. Tema ini dikontruksi oleh tiga kategori yaitu sikap mengabaikan, tingkat pendidikan, kondisi psikologis pasien.

Sikap mengabaikan merupakan seperangkat sikap yang dapat berefek negatif terhadap hubungan terapeutik yang dibangun misalnya bersikap ketus, cuek, acuh dan membuat pasien menunggu lama seperti uraian pasien dan keluarga berikut:

“...sana itu agak ketus, ... ya sayang gitu, harusnya kan ya kita udah minta maaf.. saya buatkan jadwal besok..." (ps1) “...kalau didiemin dicuekin kita merasa kaku, kagok,bingung mau ngapain bingung kalau ramah kan enak”(k5)

“...yang lama itu loh kalau control nunggunya lama banget jadikan jadi sering kesel gitu loh mas rasanya"(k2)

Tingkat pendidikan juga dianggap perawat sebagai salah satu hambatan terutama pendidikan tinggi dibanding pendidikan rendah contohnya sebagai berikut:

\footnotetext{
“...orang - orang yang high class itu karna tingkat pendidikannya tinggi itu tantangannya dia merasa pintar kadang kadang egonya tinggi...” (p1)

"kalau pengetahuan pasien rendah itu begitu diedukasi dia akan orientasinya ia saya jalani” (p2)
}

Pasien dengan level pendidikan tinggi seringkali jadi penghambat sebab cenderung merasa pintar, egonya tinggi, kekwatiran dan rasa takut yang berlebihan. Berbeda dengan pendidikan rendah mereka mudah menerima sakitnya, dan lebih mudah diberikan 
informasi dan mudah mengetahui karakternya

Psikologis yang berubah-rubah seringkali menyulitkan perawat dalam interaksi dengan pasien seperti uraian berikut:

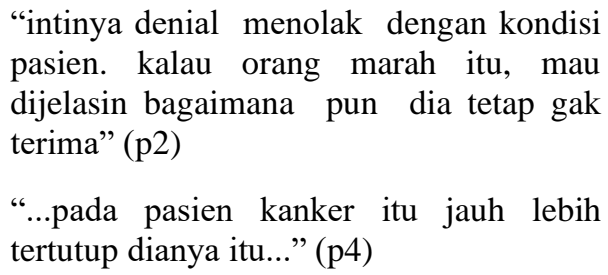

\section{Manajemen Berkomunikasi}

Manajemen berkomunikasi adalah semua hal yang dilakukan oleh perawat, pasien dan keluarga untuk memudahkan berkomunikasi satu sama laing supaya interaksi dan pertukaran informasi berjalan efektif. Tema ini terdiri dari mempersiapkan diri, validasi pengetahuan pasien dan struktur penyampaian informasi.

Pemberian informasi ke pasien perawat perlu mempersiapkan diri sebelumnya baik secara mental maupun pengetahuan, seperti dijelaskan perawat berikut:

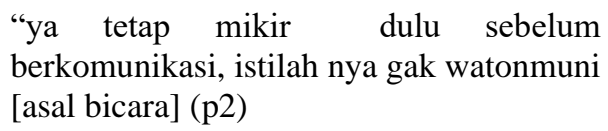

Sebelum memberikan tindakan ataupun memberikan informasi yang sensitif sebaiknya perawat mengecek pemahaman pasien dan memberikan kesempatan bertanya sehingga tidak terjadi kesalahpahaman informasi seperti uraian berikut:

"Itu saya tanya, seperti apa kemo? rata-rata bayangannya mengerikan, itu saya tanya informasinya dari mana...kemudian saya jelaskan gini-gini” (p3)

$$
\text { Langkah selanjutnya }
$$
memberikan informasi secara terstruktur dan pelan-pelan untuk memungkinkan informasi itu dipahami secara jelas, termasuk penggunaan bahasa istilah kesehatan, seperti uraian berikut:

$$
\begin{aligned}
& \text { “ya kita pelan - pelan aja, pelan-pelan } \\
& \text { kasih pengertian,” (p2) } \\
& \text {...besok ketemu lagi gimana kemarin ini- } \\
& \text { ini. Itu selalu diingatkan” (ps5) } \\
& \text { “...kita juga menjelaskan dengan bahasa- } \\
& \text { bahasanya pasien...”(p2) }
\end{aligned}
$$

\section{PEMBAHASAN}

Temuan dalam penelitian ini menggambarkan hambatan berkomunikasi efektif dan strategi yang bisa dilakukan supaya komunikasi efektif tetap terjaga. Pendekatan kualitatif fenomenologi menyediakan pemahaman yang mendalam untuk mengelaborasi secara praktis tentang hambatan dan manajemen berkomunikasi efektif dalam pelayanan kanker yang tidak hanya ditinjau dari perspektif perawat, tetapi juga persepsi pasien dan orang-orang terdekatnya.

$$
\text { Hasil penelitian ini }
$$
mengidentifikasi baik pasien, keluarga maupun perawat menyatakan komunikasi perawat-pasien/keluarga tidak terlepas dari hambatan, namun selalu ada cara untuk meminimalkan efek negatif dari hambatan tersebut Hambatan ini termasuk sikap mengabaikan tingkat pendidikan, kondisi psikologis. Bersikap mengabaikan pasien dianggap sebagai sikap kontraproduktif yang bertentangan dengan prinsip-prinsip hubungan terapeutik dengan pasien. Bersikap ketus, cuek sama pasien/keluarga, membuat pasien menunggu lama merupakan perilaku yang dapat berimplikasi negatif terhadap proses komunikasi perawatpasien/keluarga(Perez-Bret et al., 2016). 
Tabel 2.

Analisis data

\begin{tabular}{|c|c|c|c|}
\hline Pernyataan & $\begin{array}{c}\text { Formulasi } \\
\text { makna }\end{array}$ & kategori & tema \\
\hline $\begin{array}{l}\text { "...sana itu agak ketus, ... ya sayang gitu, harusnya } \\
\text { kan ya kita udah minta maaf.. saya buatkan jadwal } \\
\text { besok..." (ps1) }\end{array}$ & Ketus & \multirow{3}{*}{$\begin{array}{l}\text { Sikap } \\
\text { Mengabaikan }\end{array}$} & \multirow{10}{*}{$\begin{array}{l}\text { Hambatan } \\
\text { berkomunikasi } \\
\text { efektif }\end{array}$} \\
\hline $\begin{array}{l}\text { "cuek itu ya gak mau tau,ya ginilah yagitulah,... } \\
\text { semua pasien gak ada yang mengharapkan gitu, } \\
\text { menurut saya loh" (ps4) } \\
\text { kalau didiemin dicuekin kita merasa kaku, } \\
\text { kagok,bingung mau ngapain bingung kalau ramah } \\
\text { kan enak. (k5) } \\
\text { “...trus bilang ini uda dicek albumin uda bagus } \\
\text { juga ya gitu, trus gitu aja berjalan gitu aja, berlalu } \\
\text { gitu. (k2) }\end{array}$ & Cuek & & \\
\hline $\begin{array}{l}\text { "...yang lama itu loh kalau control nunggunya lama } \\
\text { banget jadikan jadi sering kesel gitu loh mas } \\
\text { rasanya"(k2) }\end{array}$ & $\begin{array}{l}\text { Lama } \\
\text { menunggu }\end{array}$ & & \\
\hline $\begin{array}{l}\text { “..orang berpendidikan tinggi itu sok } \\
\text { kokeanlimikir, kebanyakan mikirnya...” (p1) }\end{array}$ & $\begin{array}{l}\text { Pendidikan } \\
\text { tinggi banyak } \\
\text { mikir }\end{array}$ & \multirow{4}{*}{$\begin{array}{l}\text { Tingkat } \\
\text { pendidikan }\end{array}$} & \\
\hline $\begin{array}{l}\text { "...orang -orang yang high class itu karna tingkat } \\
\text { pendidikannya tinggi itu tantangannya dia } \\
\text { merasa pintar kadang kadang egonya tinggi..." (p1) }\end{array}$ & $\begin{array}{l}\text { Pendidikan } \\
\text { tinggi egonya } \\
\text { tinggi }\end{array}$ & & \\
\hline $\begin{array}{l}\text { "saya rasakan gini kalau pasien yang awam itu asal } \\
\text { pakai bahasan yang mudah dimengerti mereka, kita } \\
\text { menyelami karakternya itu mudah. (p1) }\end{array}$ & $\begin{array}{l}\text { Orang awam } \\
\text { mudah } \\
\text { diselami } \\
\text { karakternya }\end{array}$ & & \\
\hline $\begin{array}{l}\text { kalau pengetahuan pasien rendah itu begitu } \\
\text { diedukasi dia akan orientasinya ia saya jalani (p2) }\end{array}$ & $\begin{array}{l}\text { Pengetahuan } \\
\text { rendah lebih } \\
\text { Orientasi Ya }\end{array}$ & & \\
\hline $\begin{array}{l}\text { "..tergantung karakter nya lagi kalau karakter dia } \\
\text { itu tidak cemasan tidak ngeyel” (p1) }\end{array}$ & Cemasan & \multirow{3}{*}{$\begin{array}{l}\text { Kondisi } \\
\text { Psikologis }\end{array}$} & \\
\hline $\begin{array}{l}\text { "intinya denial menolak dengan kondisi pasien . } \\
\text { kalau orang marah itu, mau dijelasin bagaimana } \\
\text { pun dia tetap gak terima" (p2) }\end{array}$ & $\begin{array}{l}\text { Denial/ } \\
\text { anger }\end{array}$ & & \\
\hline $\begin{array}{l}\text { "...pada pasien kanker itu jauh lebih tertutup } \\
\text { dianya itu...” (p4) }\end{array}$ & $\begin{array}{l}\text { Jadi pribadi } \\
\text { tertutup }\end{array}$ & & \\
\hline $\begin{array}{l}\text { "Itu saya Tanya, seperti apa kemo ? rata-rata } \\
\text { bayangannya mengerikan, itu saya tanya } \\
\text { informasinya dari mana...kemudian saya jelaskan } \\
\text { gini-gini" (p3) }\end{array}$ & $\begin{array}{l}\text { Mengecek } \\
\text { pemahaman }\end{array}$ & \multirow{2}{*}{$\begin{array}{l}\text { Validasi } \\
\text { pengetahuan }\end{array}$} & \multirow{6}{*}{$\begin{array}{l}\text { Managemen } \\
\text { berkomunikasi }\end{array}$} \\
\hline $\begin{array}{l}\text { "yo kemarin diberi kesempatan pertanyaan tapi } \\
\text { kalau seandainya gak diberi ya kita menanyakan. } \\
\text { (k1) }\end{array}$ & feedback & & \\
\hline $\begin{array}{l}\text { "ya tetap mikir dulu sebelum berkomunikasi, } \\
\text { istilah nya gak watonmuni [asal bicara] (p2) }\end{array}$ & $\begin{array}{l}\text { Tidak asal } \\
\text { bicara }\end{array}$ & $\begin{array}{l}\text { Persiapan } \\
\text { diri }\end{array}$ & \\
\hline $\begin{array}{l}\text { "ya kita pelan - pelan aja, pelan -pelan kasih } \\
\text { pengertian," (p2) } \\
\text { "pelan-pelan sih tapi jelas" (ps6) }\end{array}$ & $\begin{array}{l}\text { Dijelaskan } \\
\text { secara pelan }\end{array}$ & \multirow{3}{*}{$\begin{array}{l}\text { Struktur } \\
\text { penyampaian } \\
\text { informasi }\end{array}$} & \\
\hline $\begin{array}{l}\text { "...mereka menjelaskan bukan hanya sekali dua } \\
\text { kali...besok ketemu lagi gimana kemarin ini-ini. Itu } \\
\text { selalu diingatkan" (ps5) }\end{array}$ & $\begin{array}{l}\text { Ada penjelasan } \\
\text { kembali }\end{array}$ & & \\
\hline $\begin{array}{l}\text { "...kita juga menjelaskan dengan bahasa-bahasanya } \\
\text { pasien..." (p2) }\end{array}$ & Bahasa pasien & & \\
\hline
\end{tabular}


Permintaan maaf dapat dilakukan untuk menyelesaikan perasaan negatif dari konflik perawat dan pasien. Zarei et al., (2019) menyatakan bahwa mengirimkan permintaan maaf di tempat kerja bisa dijadika instrumen yang logis demi meminimalkan dampak sikap negatif satu sama lain.

Pasien dengan level pendidikan tinggi seringkali lebih menantang dan kadangkala sebagai penghambat dibandingkan berpendidikan rendah sebab mereka merasa lebih tahu, lebih pintar, memiliki ego yang tinggi, kekhawatiran yang dan rasa takut yang berlebihan. Zamanzadeh et al. (2014), menyatakan bahwa pasien dengan pendidikan tinggi lebih banyak mengajukan pertanyaan dan dengan kesadaran kesehatan yang tinggi, mereka seringkali tidak yakin dengan kemampuan perawat atau informasi yang diberikan oleh perawat dan kemudian menggunakan sumber online (internet) untuk menelusuri informasi.

Diagnosis kanker dan terapinya dapat mengakibatkan perubahan fisik pada pasien. Perubahan ini misalkan pengangkatan jaringan payudara baik sebagian maupun secara total, penurunan berat badan dan rambut rontok. Perubahan fisik tersebut menimbulkan efek psikologis seperti suasana hati yang sensitif dan mood yang tidak stabil dan konsep diri pasien secara negatif. Hal ini menyulitkan perawat untuk berkomunikasi efektif dengan pasien (Chan et al., 2018; Zamanzadeh et al., 2014).

Fase penolakan dilaporkan oleh perawat dalam temuan ini sebagai salah satu tantangan berkomunikasi. Perawat mengalami hambatan untuk memberi pengertian dan pemahaman informasi kepada pasien/keluarga yang mengingkari penyakitnya. Sikap menolak menyebabkan pasien lebih banyak tertutup. Pasien pada awal diagnosis atau tahap penolakan lebih banyak diam dan menolak proses komunikasi, namun setelah melewati tahap penolakan pasien menjadi lebih aktif dalam hal berkomunikasi dengan perawat untuk mencari tahu informasi. Kemudian pasien mengurangi informasi dan menjadi depresi ketika pasien mendekati fase akhir atau menyadari status kesehatannya semakin memburuk (Matsuyama et al., 2013; Toprak et al., 2018; Warnock, 2014; Zamanzadeh et al., 2014).

Penyampaian informasi pada pasien/keluarga sebaiknya terlebih dahulu diawali dengan mengecek pemahaman pasien terhadap kondisi dan penyakitnya. Hal ini penting untuk mendapatkan persepsi pasien tentang harapan dan pengetahuan terkait penyakitnya. Persepsi pasien bervariasi mulai dengan kemoterapi itu mengerikan, dekat dengan kematian, ingin sembuh, tidak mau dioperasi, tidak ingin minum obat sampai sudah berpasrah. Validasi persepsi dimaksudkan untuk menemukan kekeliruan pemahaman dan informasi pasien mengenai penyakitnya. Kesalahpaham mengenai penyakit dan pengobatan perlu dikoreksi perawat supaya pasien memiliki pemahaman yang tepat(Abbaszadeh et al., 2014; Bumb et al., 2017; Warnock, 2014).

Komunikasi dalam pelayanan kanker harus disediakan dalam istilah-istilah yang sederhana dan menggunakan bahasa yang mudah dipahami oleh pasien, khususnya pasien yang miliki literasi kesehatan yang rendah, fokus pada poin yang paling penting, dan menjelaskan dalam bahasa yang awam ketika harus menggunakan istilah kesehatan(Murray et al., 2015). Komunikasi harus dipahami oleh semua pihak yang terlibat di dalamnya termasuk keluarga(Kourkouta \& Papathanasiou, 2014). 


\section{KESIMPULAN DAN SARAN}

Komunikasi

merupakan pondasi untuk mempromosikan kualitas perawatan kanker. Hambatan berkomunikasi seperti bersikap mengabaikan, tingkat pendidikan dan kondisi psikologis pasien kanker perlu dimanaje dengan baik dengan mengimplementasikan tindakan seperti berikut yaitu mempersiapkan diri, mevalidasi pemahaman pasien, dan penyampaian informasi secara terstruktur.

Penelitian selanjutnya diharapkan dapat menelusuri dampak dari strategi komunikasi efektif terhadap kepuasan dan kualitas hidup pasien kanker dengan menggunakan pendekatan mix-method.

\section{DAFTAR PUSTAKA}

Abbaszadeh, A., Ehsani, S. R., Akbari, M., Dopolani, F. N., Nejati, A., \& Mohammadnejad, E. (2014). Nurses' perspectives on breaking bad news to patients and their families: a qualitative content analysis. Journal of Medical Ethics and History of Medicine, 7(18), 17.

American Cancer Society. (2018). Cancer Facts and Figures 2018. In American Cancer Society.

Bumb, M., Keefe, J., Miller, L., \& Overcash, J. (2017). Breaking Bad News: An Evidence-Based Review of Communication Models for Oncology Nurses. Clinical Journal of Oncology Nursing, 21(5). https://doi.org/10.1188/17.CJON.5 73-580

Chan, E. A., Wong, F., Cheung, M. Y., \& Lam, W. (2018). Patients' perceptions of their experiences with nurse-patient communication in oncology settings: A focused ethnographic study. 1-17.

Chesnay, M. De. (2014). Nursing Research Using Phenomenology:
Qualitative Designs and Methods in Nursing (Vol. 13). Springer Publishing Company.

Ellington, L., Billitteri, J., Reblin, M., \& Clayton, M. F. (2017). Spiritual Care Communication in Cancer Patients. Seminars in Oncology Nursing, 33(5), 517-525. https://doi.org/10.1016/j.soncn.201 7.09.002

Hasan, I., \& Rashid, T. (2016). Clinical Communication, Cancer Patients \& Considerations to Minimize the Challenges. Journal of Cancer Therapy, 7, 107-113. https://doi.org/10.4236/jct.2016.72 012

Holloway, I., Wheeler, S., \& Holloway, I. (2010). Qualitative research in nursing and healthcare (3rd editio). Wiley-Blackwell. https://doi.org/10.1017/CBO97811 07415324.004

Khoshnazar, T. A. K., Rassouli, M., Akbari, M. E., Lotfi-Kashani, F., Momenzadeh, S., Rejeh, N., \& Mohseny, M. (2016). Communication needs of patients with breast cancer: A qualitative study. Indian Journal of Palliative Care, 22(4), 402-409. https://doi.org/10.4103/09731075.191763

Kourkouta, L., \& Papathanasiou, I. (2014). Communication in Nursing Practice. Materia Socio Medica, 26(1), 65. https://doi.org/10.5455/msm.2014. 26.65-67

Matsuyama, R. K., Kuhn, L. A., Molisani, A., \& Wilson-Genderson, M. C. (2013). Cancer patients' information needs the first nine months after diagnosis. Patient Education and Counseling, 90(1), 96-102.

https://doi.org/10.1016/j.pec.2012. 09.009 
Murray, C. D., McDonald, C., \& Atkin, H. (2015). The communication experiences of patients with palliative care needs: A systematic review and meta-synthesis of qualitative findings. Palliative \& Supportive Care, 13(2), 369-383. https://doi.org/10.1017/S14789515 14000455

Perez-Bret, E., Altisent, R., \& Rocafort, J. (2016). Definition of compassion in healthcare: a systematic literature review. International Journal of Palliative Nursing, 22(12), 599606.

https://doi.org/10.12968/ijpn.2016. 22.12.599

Polit, D. F., \& Beck, C. T. (2012). Nursing research: Generating and assessing evidence for nursing practice (9th ed). Lippincott.

Prip, A., Pii, K. H., Møller, K. A., Nielsen, D. L., Thorne, S. E., \& Jarden, M. (2019). Observations of the communication practices between nurses and patients in an oncology outpatient clinic. European Journal of Oncology Nursing, 40(December 2018), 120125.

https://doi.org/10.1016/j.ejon.2019. 03.004

Riskesdas. (2018). Riset Kesehatan Dasar (RISKESDAS) 2018. Kementerian Kesehatan Badan Penelitian dan Pengembangan Kesehatan.

Stephens, F. O., \& Aigner, K. R. (2016). Basics of oncology (2nd ed.). Springer Cham Heidelberg.

Toprak, F. Ü., Kutlutürkan, S., \& Erenel, A. Ş. (2018). Symptoms
Experienced and Information Needs of Women Receiving Chemotherapy. Asia-Pacific Journal of Oncology Nursing, 5(2), 178-183.

https://doi.org/10.4103/apjon.apjon

Warnock, C. (2014). Breaking bad news: issues relating to nursing practice. Nursing Standard, 28(45), 51-58.

Weert, J. C. M. Van, Bolle, S., Dulmen, S. Van, \& Jansen, J. (2013). Patient Education and Counseling Older cancer patients ' information and communication needs: What they want is what they get? Patient Education and Counseling, 92(3), 388-397.

https://doi.org/10.1016/j.pec.2013. 03.011

WHO. (2018). FactSheet of Cancer. World Health Organization. http://www.who.int/newsroom/fact-sheets/detail/cancer

Zamanzadeh, V., Ghahramanian, A., Rassouli, M., Abbaszadeh, A., Nikanfar, A., \& Alavi-Majd, H. (2014). Factors Influencing communication between the patients with cancer and their nurses in oncology wards. Indian Journal of Palliative Care, 20(1), 12. https://doi.org/10.4103/09731075.125549

Zarei, B., Salmabadi, M., Amirabadizadeh, A., \& Vagharseyyedin, S. A. (2019). Empathy and cultural competence in clinical nurses: a structural equation modelling approach. Nursing Ethics, 1-11. https://doi.org/10.1177/096973301 8824794 